\section{Waiting for evidence?}

The authors state electronic health records (with some decision support) will save lives and improve outcomes. Really? E-health has never consistently and demonstrably done either. Why should more information, alone, lead to better outcomes? Were physicians who did not quickly adopt thalidomide, rofecoxib, gastric freezing, or EC-IC bypass because of the lack of evidence for benefit and safety "dithering"? A conservative approach, weighing pros and cons, and watchful waiting for evidence of benefit without harms or unintended consequences should not be mistaken for dithering. I agree Canadians deserve nothing less than physicians who use proven effective interventions and technologies to help their patients feel better and live longer. Until e-health has proven itself safe, effective and affordable, maybe festina lente is rational: make haste, slowly.

\section{Sumit R. Majumdar MD MPH}

Associate professor, University of Alberta, Edmonton, Alta.

\section{REFERENCE}

1. McGrail K, Law M, Hébert PC. No more dithering on e-health: let's keep patients safe instead. CMAJ 2010;182:535.

For the full letter, go to: www.cmaj.ca/cgi/eletters /cmaj.092189v1\#299106

DOI:10.1503/cmaj.110-2051

\section{Film "interventions"}

McDonald's review of Filmmaker-inResidence $e^{1}$ draws attention to a thoughtprovoking project by Katerina Cizek. However, he refuses to believe what he sees: that people living in poverty have something to say that is worth listening to. In Hand-held (Young Parents No Fixed Address), he feels the young women featured appear too "smart, articulate and insightful," and don't match his idea of the homeless. As someone who has worked with homeless patients throughout my residency at St. Michael's Hospital, I did not find the film to be misleading at all. Rather, it accurately captures the voices of a population usually silenced. I recently invited Cizek to present her films to undergraduates in a course that I teach. She rightfully labels her films as "interventions." They are about change. While McDonald may find it difficult to change his beliefs about certain people, Cizek challenges us to listen to, rather than speak for, marginalized populations.

\section{Andrew D. Pinto MD}

St. Michael's Hospital, Toronto, Ont.

\section{REFERENCE}

1. McDonald D. Films for health. CMAJ 2010;182: 177-8.

For the full letter, go to: www.cmaj.ca/cgi/eletters /182/2/177\#283659

DOI:10.1503/cmaj.110-2048

\section{Something bad? Or good?}

Dr. Huang observes that in the very elderly, a serial decline in grip strength may signal that something bad is about to happen. I assume he means that the patient is likely to die in the near future. Arguably, the decline in grip strength is an inevitable change that will occur in the majority of octogenarians barring sudden death (or the development of immortality). From a population health perspective, advanced age at the time of death preceded by a decline in grip strength may be the best outcome one should hope for. An obvious conclusion not stated by Dr. Huang is that in frail and failing elderly patients, palliative goals should be integrated into the care plan.

\section{Stephen R. Workman MD}

Dalhousie University, Halifax, NS

\section{REFERENCE}

1. Huang AR. Getting a grip on aging. CMAJ 2010; $182: 423$

For the full letter, go to: www.cmaj.ca/cgi/eletters /182/5/423\#316127

DOI:10.1503/cmaj.110-2055

\section{Irritability and CATCH}

RE: "CATCH: a clinical decision rule for the use of computed tomography in children with minor head injury."1 This team has done a great job in giving us rural physicians a guiding hand in a clinically difficult situation. However, one thing caught my eye. It was the concept of "irritability on examination" as one of the major high-risk criteria for whether to send a child for a CT scan, which usually includes contacting a tertiary hospital, arranging transport and finding an accepting physician. This point needs more clarity. On an average day in the emergency department, irritability is not uncommon, especially in younger children. There are at least a few who become irritable at the thought of having a light shone in their eyes or an otoscope placed in their ears. If every child with a minor head injury who becomes irritable when examined starts getting a CT scan, this could increase the number done, rather than decrease it, which would be counterproductive to the aim of the study.

\section{Bret E. Batchelor MD \\ Oliver, BC}

\section{REFERENCE}

1. Osmond MH, Klassen TP, Wells GA, et al. CATCH: a clinical decision rule for the use of computed tomography in children with minor head injury. CMAJ 2010;182:341-8.

For the full letter, go to: www.cmaj.ca/cgi/eletters /182/4/341\#307752

DOI:10.1503/cmaj.110-2050

\section{Correction}

The article "Films for health,"1 published Feb. 9, stated that Pax Chingawale was on antiretroviral drugs. In fact, he is not. CMAJ regrets the error.

\section{REFERENCE \\ 1. McDonald D. Films for Health. CMAJ 2010;182: 177-8.}

DOI:10.1503/cmaj.110-2053

\section{Letters to the editor}

In submitting a letter, you automatically consent to have it appear online and/or in print. All letters accepted for print will be edited by $C M A J$ for space and style. Most references and multiple authors' names and full affiliations will appear online only. (The full version of any letter accepted for print will be posted at cmaj.ca.) 